\title{
An Equilibrium Model of Interbank Networks Based on Variational Inequalities
}

\author{
Shouwei Li and Jianmin He \\ School of Economics and Management, Southeast University, Nanjing, Jiangsu 211189, China \\ Correspondence should be addressed to Shouwei Li; lswseu@126.com
}

Received 14 March 2013; Revised 15 October 2013; Accepted 16 October 2013

Academic Editor: Shao-Ming Fei

Copyright (C) 2013 S. Li and J. He. This is an open access article distributed under the Creative Commons Attribution License, which permits unrestricted use, distribution, and reproduction in any medium, provided the original work is properly cited.

\begin{abstract}
We develop an equilibrium model of credit network and trust network in the interbank market. We consider two kinds of decision makers including banks with liquidity surplus and banks with liquidity shortage. We model the behavior of the decision makers, derive the equilibrium conditions, and establish the variational inequality formulation for interbank credit network and trust network. We then utilize the variational inequality formulation to obtain qualitative properties of the equilibrium pattern in terms of existence and uniqueness.
\end{abstract}

\section{Introduction}

Interbank markets are among the most important in financial systems. They allow exchanges among financial institutions, facilitating the allocation of the liquidity surplus to banks with liquidity shortage. A particular feature in interbank markets is the threat of systemic risk, where the failure of one bank spreads to other banks, through interbank connections. Notwithstanding, the global financial crisis, which burst in August 2007, has shown the dark side of interbank connections. In recent years, interbank connections have received significant attention in the literature. However, the literature mainly focuses on network structure, based on which the effect of systemic risk is simulated.

The intricate structure of interbank connections can be captured by using a network representation, and this network is called credit network in this paper. Actually, there is large literature justifying the existence of the heterogeneity of interbank credit networks in real world banking systems, such as a random network topology [1], a small-world network topology [2], a scale-free network topology [3], tiered network topology [4], and so on. Some researches focus on the explanation of how they emerge, for instance, Inaoka et al. [3] construct a growing model for banking networks to explain that a power-law distribution is a self-organized critical phenomenon; Teteryatnikova [5] and Li and He [6] provide different methods to construct tiered credit networks in interbank markets. Network models have proven to be very helpful for the study of shock propagation and a system's resilience to contagion [7], and there has been growing literature to simulate the effect of systemic risk based on interbank credit network models. There are many significant studies in this area, such as Iori et al. [8], Nier et al. [9], Canedo and Jaramillo [10], Gai and Kapadia [11], May and Arinaminpathy [12], Berman et al. [13], Gai et al. [14], Haldane and May [15], Anand et al. [16], Heise and Kuehn [17], Lenzu and Tedeschi [18], Mastromatteo et al. [19], and so forth.

The above relevant literature makes it clear that interbank credit network structures play an important role in the resilience of banking systems to systemic risk. Therefore, analyzing credit lending behavior in the interbank market is very useful in understanding the formation of interbank credit networks. It is also important for monetary authorities, since the interbank market lies at the heart of monetary policy. Actually, interbank lending behavior is a multiobjective decision making problem among banks. Trust is ubiquitous in social and economic activity, and credit markets exemplify the way in which trust lies at the very foundation of modern financial systems [20]. Generally, there are no sponsion or mortgages in the credit lending relationships. Therefore, interbank trust relationship is an important factor in the decision of interbank credit lending, except the term and interest rate of loan and so on. In this paper, the network 
TABLE 1: Notations for the equilibrium model.

\begin{tabular}{ll}
\hline Notations & Description \\
\hline$M$ & The number of banks in the interbank market \\
\hline$N_{t}$ & Trust network in the interbank market \\
\hline$N_{c}$ & Credit network in the interbank market \\
\hline$i$ & A bank with liquidity surplus, $i=1, \ldots, M_{0}$ \\
\hline$j$ & A bank with liquidity shortage, $j=1, \ldots, M-M_{0}$ \\
\hline$h_{i j}$ & The trust level of bank $i$ to bank $j, 0 \leq h_{i j} \leq 1$ \\
\hline$v_{i j}$ & $\begin{array}{l}\text { The value of the trust level } h_{i j} \text { for bank } j, \\
S_{i j}\left(h_{i j}\right)=a_{i j} h_{i j}+c_{i j}, a_{i j} \text { and } c_{i j} \text { are constants, } a_{i j}>0\end{array}$ \\
\hline$D_{j}$ & The scale of liquidity surplus of bank $i$ \\
\hline$q_{i j}$ & The scale of liquidity shortage of bank $j$ \\
\hline$l_{i}$ & The scale of credit lending of bank $j$ from bank $i$ \\
\hline$b_{j}$ & The lending rate of bank $i$ \\
\hline$p_{i j}$ & The borrowing rate of bank $j$ \\
\hline$b_{i j}$ & $\begin{array}{l}\text { The interest rate for the credit lending } q_{i j}, \\
p_{i j}=p_{i j}\left(l_{i}, b_{j}\right)\end{array}$ \\
\hline$r_{i j}$ & $\begin{array}{l}\text { The opportunity cost of bank } i \text { for the credit lending } \\
q_{i j}, b_{i j}=b_{i j}\left(q_{i j}\right)\end{array}$ \\
\hline$f_{i j}$ & $\begin{array}{l}\text { The risk faced by bank } i \text { for the credit lending } q_{i j}, \\
r_{i j}=r_{i j}\left(q_{i j}, h_{i j}, p_{i j}\right)\end{array}$ \\
\hline $\begin{array}{l}\text { The borrowing cost of bank } j \text { for the credit lending } \\
q_{i j}, f_{i j}=f_{i j}\left(q_{i j}, h_{i j}, p_{i j}\right)\end{array}$
\end{tabular}

consisted by interbank trust relationships is called trust network. To the best of our knowledge, however, there is no research to analyze the interaction between credit network and trust network in the interbank market. Motivated by this consideration, in this paper, we construct a multiple objective decision model and analyze the equilibrium condition of interbank credit network and trust network. Our paper is organized as follows. Section 2 describes the behavior of banks and their optimality conditions and analyzes the equilibrium condition. Conclusions are drawn in Section 3.

\section{The Equilibrium Model}

In this section, we construct the equilibrium model of credit network and trust network in the interbank market. Assuming that there are $M$ banks in the interbank market. We use the notations $N_{t}$ and $N_{c}$ to represent trust network and credit network, respectively, where edges between nodes in $N_{t}$ represent interbank trust relationships and edges between nodes in $N_{c}$ represent interbank credit lending relationships. The majority of the notations for the model are given in Table 1. In this paper, we assume that the value of interbank trust relationship is a linear function; the interest rate of the credit lending between bank $i$ and bank $j$ depends on the lending rate of bank $i$ and the borrowing rate of bank $j$; the opportunity cost of a bank depends on the scale of its credit lending; the risk faced by a creditor bank is determined by the scale and interest rate of the credit lending and its trust level to the debtor bank; the borrowing cost of a bank is a function of the scale and interest rate of the credit lending and the interbank trust level. The functions $b_{i j}, r_{i j}$, and $f_{i j}(i=$ $1, \ldots, M_{0}, j=1, \ldots, M-M_{0}$ ) given in Table 1 are assumed to be continuously differentiable and convex. In Table $1, M, M_{0}$, $S_{i}, D_{j}, q_{i j}, l_{i}, b_{j}$, and $p_{i j}$ are observable, and $h_{i j}, v_{i j}, b_{i j}, r_{i j}$, and $f_{i j}$ are nonobservable.

2.1. Bank Behavior and Optimality Conditions. We now describe the behavior of banks in the interbank market and their optimality conditions. For bank $i$ with liquidity surplus, we assume that it faces a multicriteria decision making problem, with the objectives reflecting revenue maximization, risk minimization, and opportunity cost minimization, and they can be expressed, respectively, as

$$
\begin{aligned}
& \operatorname{maximize} \sum_{j=1}^{M-M_{0}} q_{i j} p_{i j}\left(l_{i}, b_{j}\right), \\
& \operatorname{minimize} \sum_{j=1}^{M-M_{0}} r_{i j}\left(q_{i j}, h_{i j}, p_{i j}\left(l_{i}, b_{j}\right)\right), \\
& \operatorname{minimize} \sum_{j=1}^{M-M_{0}} b_{i j}\left(q_{i j}\right) .
\end{aligned}
$$

The optimization problem of bank $i$ with liquidity surplus can, thus, be expressed as

$$
\begin{array}{ll}
\operatorname{maximize} & \sum_{j=1}^{M-M_{0}}\left(q_{i j} p_{i j}\left(l_{i}, b_{j}\right)-r_{i j}\left(q_{i j}, h_{i j}, p_{i j}\left(l_{i}, b_{j}\right)\right)-b_{i j}\left(q_{i j}\right)\right), \\
\text { subject to: } & \sum_{j=1}^{M-M_{0}} q_{i j} \leq S_{i}, \\
& q_{i j} \geq 0 \\
& 0 \leq h_{i j} \leq 1 .
\end{array}
$$

We assume that $h_{i j}$ and $q_{i j}$ are at the equilibrium values denoted by $*$. From (2), it can be seen that the objective function is continuously differentiable and concave, and the feasible set is closed and convex. Therefore, the optimality conditions for all banks with liquidity surplus simultaneously can be expressed as the following inequality based on the Variational Inequalities Theory [21]: $h^{*}=\left(h_{i j}^{*}\right) \in R_{+}^{M_{0}\left(M-M_{0}\right)}$, $q^{*}=\left(q_{i j}^{*}\right) \in R_{+}^{M_{0}\left(M-M_{0}\right)}$, such that

$$
\begin{aligned}
\sum_{i=1}^{M_{0}} \sum_{j=1}^{M-M_{0}}[ & \left(\frac{\partial b_{i j}\left(q_{i j}^{*}\right)}{\partial q_{i j}}+\frac{\partial r_{i j}\left(q_{i j}^{*}, h_{i j}^{*}, p_{i j}\left(l_{i}, b_{j}\right)\right)}{\partial q_{i j}}-p_{i j}\left(l_{i}, b_{j}\right)\right) \\
& \left.\times\left(q_{i j}-q_{i j}^{*}\right)+\frac{\partial r_{i j}\left(q_{i j}^{*}, h_{i j}^{*}, p_{i j}\left(l_{i}, b_{j}\right)\right)}{\partial h_{i j}}\left(h_{i j}-h_{i j}^{*}\right)\right]
\end{aligned}
$$

$\geq 0$. 
In this paper, we assume that the liquidity in the interbank market is sufficient and can meet the demands of all banks with liquidity shortage. In a similar way to the above analysis, we can know that the optimization problem of bank $j$ with liquidity shortage, with the objectives reflecting borrowing cost minimization and trust value maximization, can be expressed as

$$
\begin{aligned}
\operatorname{minimize} & \sum_{i=1}^{M_{0}}\left[f_{i j}\left(q_{i j}, h_{i j}, p_{i j}\left(l_{i}, b_{j}\right)\right)-v_{i j}\left(h_{i j}\right)\right], \\
\text { subject to: } & \sum_{i=1}^{M_{0}} q_{i j}=D_{i}, \\
& q_{i j} \geq 0 \\
& 0 \leq h_{i j} \leq 1 .
\end{aligned}
$$

And the optimality conditions for all banks with liquidity shortage simultaneously can be expressed as the following inequality: $h^{*}=\left(h_{i j}^{*}\right) \in R_{+}^{M_{0}\left(M-M_{0}\right)}, q^{*}=\left(q_{i j}^{*}\right) \in R_{+}^{M_{0}\left(M-M_{0}\right)}$, such that

$$
\begin{aligned}
\sum_{j=1}^{M-M_{0}} \sum_{i=1}^{M_{0}}[ & \frac{\partial f_{i j}\left(q_{i j}^{*}, h_{i j}^{*}, p_{i j}\left(l_{i}, b_{j}\right)\right)}{\partial q_{i j}} \\
& \times\left(q_{i j}-q_{i j}^{*}\right)+\left(\frac{\partial f_{i j}\left(q_{i j}^{*}, h_{i j}^{*}, p_{i j}\left(l_{i}, b_{j}\right)\right)}{\partial h_{i j}}-a_{i j}\right) \\
& \left.\times\left(h_{i j}-h_{i j}^{*}\right)\right] \geq 0 .
\end{aligned}
$$

2.2. The Equilibrium Condition. In equilibrium, the optimality conditions for all banks with liquidity surplus and the optimality conditions for all banks with liquidity shortage must be simultaneously satisfied. We now formally state the equilibrium condition of interbank credit network and trust network as following.

Definition 1. The equilibrium state of interbank credit network and trust network is one where interbank credit scales and trust levels satisfy the sum of conditions in (3) and (5).

Theorem 2. The equilibrium condition governing interbank credit network and trust network is equivalent to the solution to the variational inequality problem given by $h^{*}=\left(h_{i j}^{*}\right) \epsilon$ $R_{+}^{M_{0}\left(M-M_{0}\right)}, q^{*}=\left(q_{i j}^{*}\right) \in R_{+}^{M_{0}\left(M-M_{0}\right)}$, satisfying

$$
\begin{aligned}
\sum_{i=1}^{M_{0}} \sum_{j=1}^{M-M_{0}}[ & \left(\frac{\partial b_{i j}\left(q_{i j}^{*}\right)}{\partial q_{i j}}+\frac{\partial r_{i j}\left(q_{i j}^{*}, h_{i j}^{*}, p_{i j}\left(l_{i}, b_{j}\right)\right)}{\partial q_{i j}}\right. \\
& \left.+\frac{\partial f_{i j}\left(q_{i j}^{*}, h_{i j}^{*}, p_{i j}\left(l_{i}, b_{j}\right)\right)}{\partial q_{i j}}-p_{i j}\left(l_{i}, b_{j}\right)\right) \\
& \times\left(q_{i j}-q_{i j}^{*}\right)
\end{aligned}
$$

$$
\begin{aligned}
& +\left(\frac{\partial r_{i j}\left(q_{i j}^{*}, h_{i j}^{*}, p_{i j}\left(l_{i}, b_{j}\right)\right)}{\partial h_{i j}}\right. \\
& \left.+\frac{\partial f_{i j}\left(q_{i j}^{*}, h_{i j}^{*}, p_{i j}\left(l_{i}, b_{j}\right)\right)}{\partial h_{i j}}-a_{i j}\right) \\
& \left.\times\left(h_{i j}-h_{i j}^{*}\right)\right] \geq 0 .
\end{aligned}
$$

After algebraic simplification, the summation of (3) and (5) yields the variational inequality (6). According to the above definition, Theorem 2 can be easily proved. Now we discuss some properties of solutions of the given variational inequality (6), especially the existence and uniqueness. The existence of the solutions is very important, because if there is no existence of the solutions, the model constructed in this paper is without any connotation and practical significance. For easy reference in the following, variational inequality problem (6) can be rewritten in standard variational inequality form [21] as follows:

$$
\left\langle F\left(X^{*}\right)^{T}, X-X^{*}\right\rangle \geq 0,
$$

where $X=(h, q), F(X)=\left(F_{1}(X), F_{2}(X)\right)$, the term $\langle\cdot, \cdot\rangle$ denotes the inner product, and $F_{1}(X)$ and $F_{2}(X)$ are expressed as follows:

$$
\begin{aligned}
& F_{1}(X)=\sum_{i=1}^{M_{0}} \sum_{j=1}^{M-M_{0}}[ \frac{\partial r_{i j}\left(q_{i j}, h_{i j}, p_{i j}\left(l_{i}, b_{j}\right)\right)}{\partial h_{i j}} \\
&\left.+\frac{\partial f_{i j}\left(q_{i j}, h_{i j}, p_{i j}\left(l_{i}, b_{j}\right)\right)}{\partial h_{i j}}-a_{i j}\right], \\
& F_{2}(X)=\sum_{i=1}^{M_{0}} \sum_{j=1}^{M-M_{0}}\left[\frac{\partial b_{i j}\left(q_{i j}\right)}{\partial q_{i j}}+\frac{\partial r_{i j}\left(q_{i j}, h_{i j}, p_{i j}\left(l_{i}, b_{j}\right)\right)}{\partial q_{i j}}\right. \\
&\left.+\frac{\partial f_{i j}\left(q_{i j}, h_{i j}, p_{i j}\left(l_{i}, b_{j}\right)\right)}{\partial q_{i j}}-p_{i j}\left(l_{i}, b_{j}\right)\right] .
\end{aligned}
$$

Theorem 3. Assume that the functions $b_{i j}, r_{i j}$, and $f_{i j}$ are continuously differentiable and convex, for all $i$ and $j$, and one of them is a strictly convex function. Then there must be a unique pattern $\left(h^{*}, q^{*}\right)$ satisfying the equilibrium condition. In other words, a unique solution $\left(h^{*}, q^{*}\right)$ exists in the variational inequality (6).

Proof. Let $K=\left\{(h, q) \mid 0 \leq h_{i j} \leq 1,0 \leq q_{i j} \leq \rho, \sum_{j=1}^{M-M_{0}} q_{i j} \leq\right.$ $\left.S_{i}, \sum_{i=1}^{M_{0}} q_{i j}=D_{j}\right\}$, where $\rho$ is a constant and denotes the total scale of liquidity surplus in the interbank market. It can be seen that the feasible set $K$ is a compact (closed and bounded) convex set, and $F(X)$ is continuous on $K$. Therefore, we can know that the variational inequality problem (6) admits at least one solution $\left(h^{*}, q^{*}\right)$ based on the Theorem of Nagurney [22]. In a similar way to Theorems 6 and 7 of Nagurney 
and Ke [23], we know that the vector function $F$ that enters the variational inequality (7) is strictly monotonous (i.e., $\left.\left\langle\left(F\left(X^{\prime}\right)-F\left(X^{\prime \prime}\right)\right)^{T}, X^{\prime}-X^{\prime \prime}\right\rangle>0, \forall X^{\prime}, X^{\prime \prime} \in K, X^{\prime} \neq X^{\prime \prime}\right)$, and then there must be a unique pattern $\left(h^{*}, q^{*}\right)$ satisfying the variational inequality problem (6).

\section{Conclusions}

Interbank credit lending behavior actually is a multiobjective decision making problem among banks based on interbank trust relationships. In this paper, we developed a framework for the formulation and qualitative analysis of solutions to the equilibrium problem of credit network and trust network in the interbank market.

We described the behavior of the decision makers concluding banks with liquidity surplus and banks with liquidity shortage, where banks with surplus faced a multicriteria decision making problem consisting of revenue maximization, opportunity cost minimization, and risk minimization, and banks with liquidity shortage faced bicriteria decision making problem consisting of borrowing cost minimization and trust value maximization. We derived the optimality conditions for banks with liquidity surplus as well as banks with liquidity shortage, under suitable assumptions of the underlying functions, along with the equilibrium conditions. Moreover, we derived the variational inequality formulation of the governing equilibrium condition of interbank credit network and trust network. The variational inequality was then utilized to obtain the existence of the equilibrium credit scale and trust level pattern as well as uniqueness.

Hence, under the interaction of interbank credit network and trust network, using the variational inequality formulation, we can obtain the equilibrium credit scale and trust level pattern to make the optimality conditions for all banks be simultaneously satisfied. At the moment, the interbank market is under the equilibrium state, and the whole interest of the interbank market is the largest, which is useful to enhance the resilience of the interbank market to systemic risk. If the equilibrium condition is not fulfilled, banks with liquidity surplus will not obtain the maximum profit, and banks with liquidity shortage will obtain liquidity at relatively larger cost or their liquidity needs are not met, which may trigger default risk and contagion risk. In order to maintain the equilibrium of the bank network system, the central bank should keep the liquidity in the interbank market sufficient, and banks should enhance their credit level and strengthen their cooperation with other banks.

\section{Acknowledgments}

This research is supported by NSFC (no. 71071034, no. 71201023, and no. 71273048), NBRR (no. 2010CB328104-02), and Humanities and Social Science Youth Foundation of the Ministry of Education of China (no. 12YJC630101).

\section{References}

[1] G. Iori, G. De Masi, O. V. Precup, G. Gabbi, and G. Caldarelli, "A network analysis of the Italian overnight money market,"
Journal of Economic Dynamics and Control, vol. 32, no. 1, pp. 259-278, 2008.

[2] M. Boss, H. Elsinger, M. Summer, and S. Thurner, "Network topology of the interbank market," Quantitative Finance, vol. 4, no. 6, pp. 677-684, 2004.

[3] H. Inaoka, H. Takayasu, T. Shimizu, T. Ninomiya, and K. Taniguchi, "Self-similarity of banking network," Physica A, vol. 339, no. 3-4, pp. 621-634, 2004.

[4] C. Upper and A. Worms, "Estimating bilateral exposures in the German interbank market: is there a danger of contagion?" European Economic Review, vol. 48, no. 4, pp. 827-849, 2004.

[5] M. Teteryatnikova, "Resilience of the interbank network to shocks and optimal bailout strategy: advantages of "tiered" banking systems," European University Institute Working Paper, European University, Barcelona, Geneva, 2009.

[6] S. Li and J. He, "Fitness model for tiered structure in the interbank market," Complexity, vol. 17, pp. 37-43, 2012.

[7] F. Allen and A. Babus, "Networks in finance," in The Network Challenge, P. Kleindorfer, J. Wind, and R. E. Gunther, Eds., Wharton School, Upper Saddle River, NJ, USA, 2009.

[8] G. Iori, S. Jafarey, and F. G. Padilla, "Systemic risk on the interbank market," Journal of Economic Behavior and Organization, vol. 61, no. 4, pp. 525-542, 2006.

[9] E. Nier, J. Yang, T. Yorulmazer, and A. Alentorn, "Network models and financial stability," Journal of Economic Dynamics and Control, vol. 31, no. 6, pp. 2033-2060, 2007.

[10] J. M. D. Canedo and S. M. Jaramillo, "A network model of systemic risk: stress testing the banking system," Intelligent Systems in Accounting, Finance and Management, vol. 16, no. 1-2, pp. 87-110, 2009.

[11] P. Gai and S. Kapadia, "Contagion in financial networks," Proceedings of the Royal Society A, vol. 466, no. 2120, pp. 24012423, 2010.

[12] R. M. May and N. Arinaminpathy, "Systemic risk: the dynamics of model banking systems," Journal of the Royal Society Interface, vol. 7, no. 46, pp. 823-838, 2010.

[13] P. Berman, B. Dasgupta, L. Kaligounder et al., "On vulnerability of banking networks," http://arxiv.org/abs/1110.3546.

[14] P. Gai, A. Haldane, and S. Kapadia, "Complexity, concentration and contagion," Journal of Monetary Economics, vol. 58, no. 5, pp. 453-470, 2011.

[15] A. G. Haldane and R. M. May, "Systemic risk in banking ecosystems," Nature, vol. 469, no. 7330, pp. 351-355, 2011.

[16] K. Anand, S. Brennan, P. Gai et al., "A network model of financial system resilience," Journal of Economic Behavior \& Organization, vol. 85, pp. 219-235, 2013.

[17] S. Heise and R. Kuehn, "Derivatives and credit contagion in interconnected networks," The European Physical Journal B, vol. 85, pp. 1-19, 2012.

[18] S. Lenzu and G. Tedeschi, "Systemic risk on different interbank network topologies," Physica A, vol. 391, no. 18, pp. 4331-4341, 2012.

[19] I. Mastromatteo, E. Zarinelli, and M. Marsili, "Reconstruction of financial networks for robust estimation of systemic risk," Journal of Statistical Mechanics, vol. 2012, no. 3, Article ID P03011, 2012.

[20] K. Anand, P. Gai, and M. Marsili, "Financial crises and the evaporation of trust," http://arxiv.org/abs/0911.3099.

[21] A. Nagurney, Network Economics: A Variational Inequality Approach, Second and Revised ed, Kluwer Academic, Dodrecht, The Netherlands, 1999. 
[22] A. Nagurney, "Supernetworks: the science of complexity," Journal of University of Shanghai for Science and Technology, vol. 33, no. 3, pp. 205-228, 2011.

[23] A. Nagurney and K. Ke, "Financial networks with intermediation: risk management with variable weights," European Journal of Operational Research, vol. 172, no. 1, pp. 40-63, 2006. 


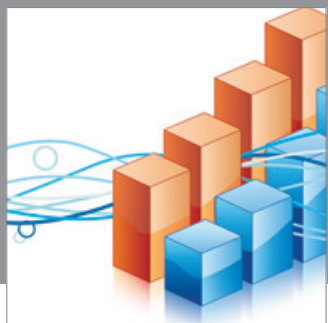

Advances in

Operations Research

mansans

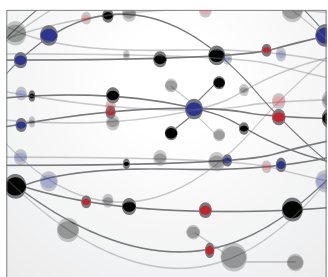

The Scientific World Journal
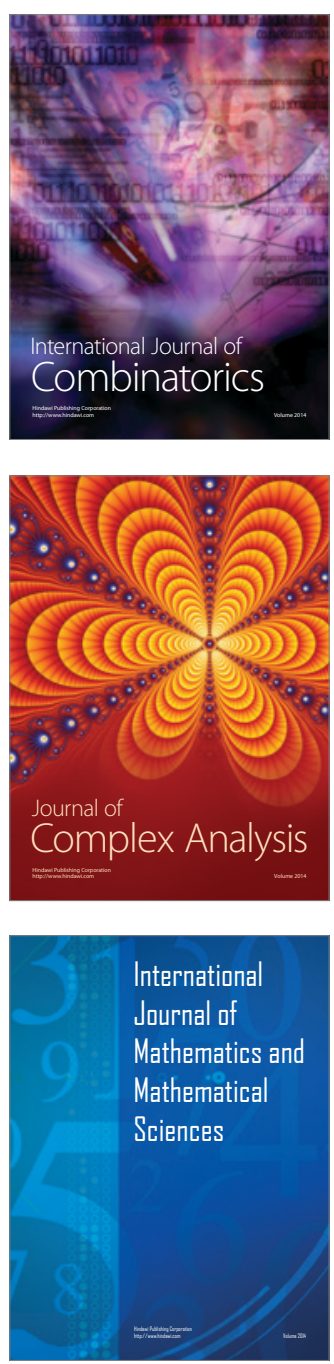
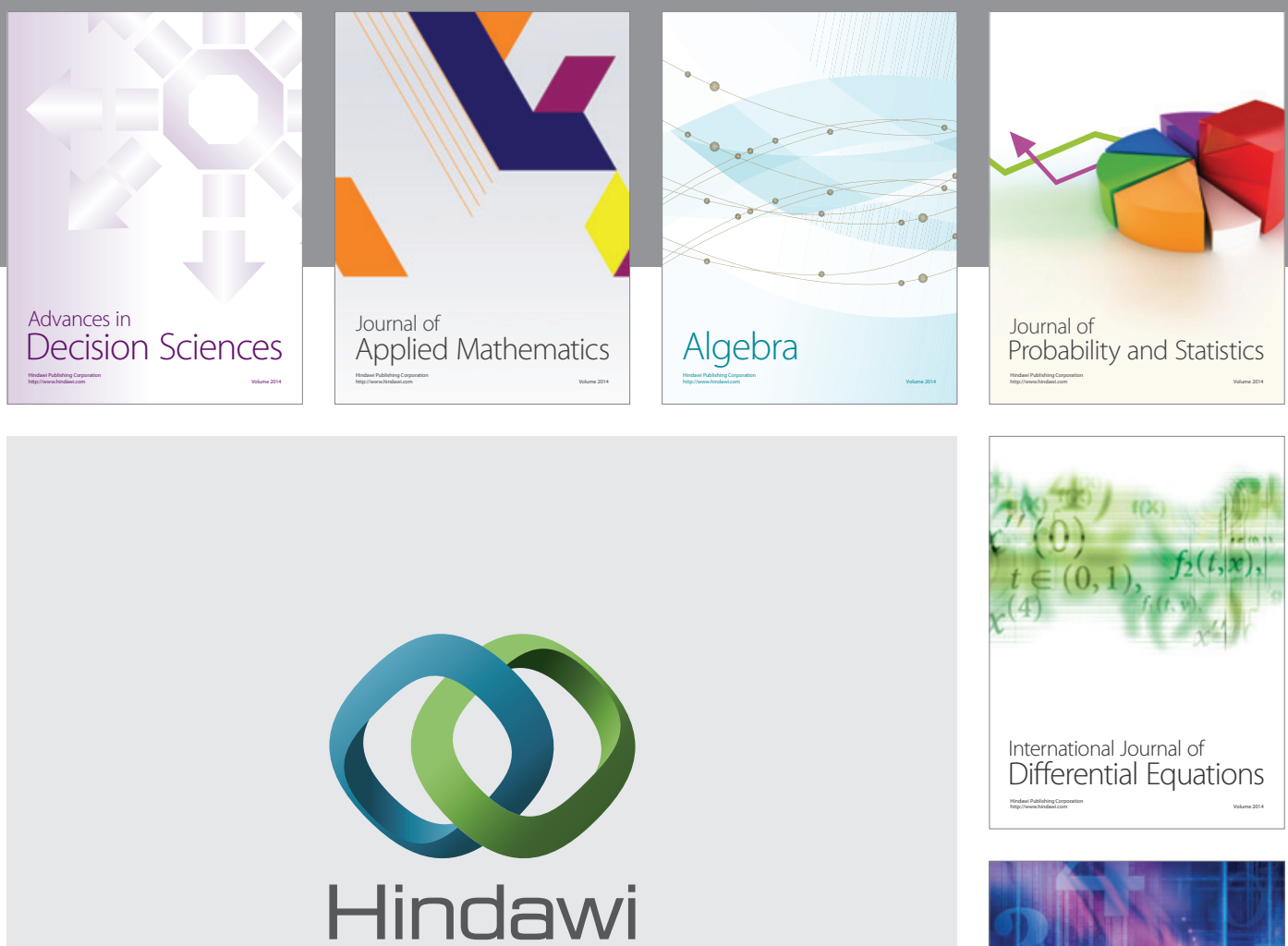

Submit your manuscripts at http://www.hindawi.com
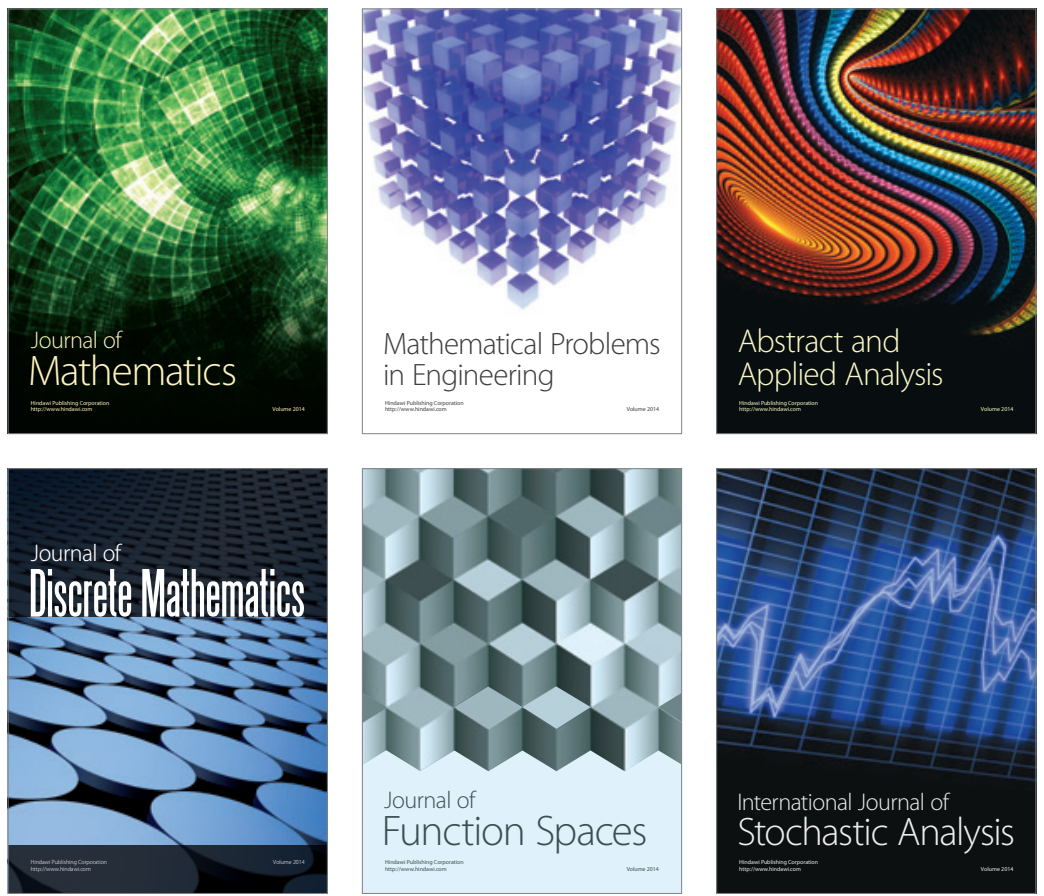

Journal of

Function Spaces

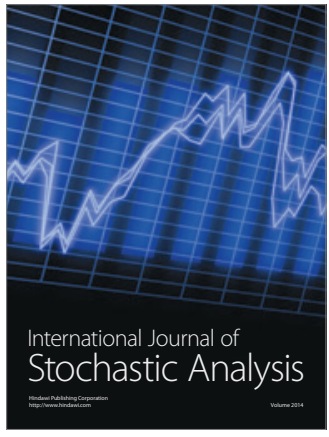

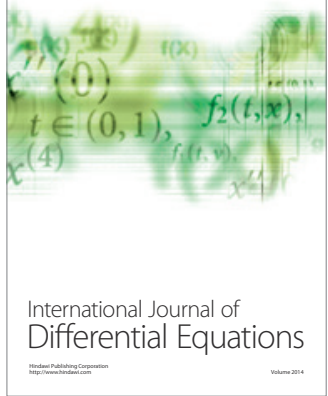
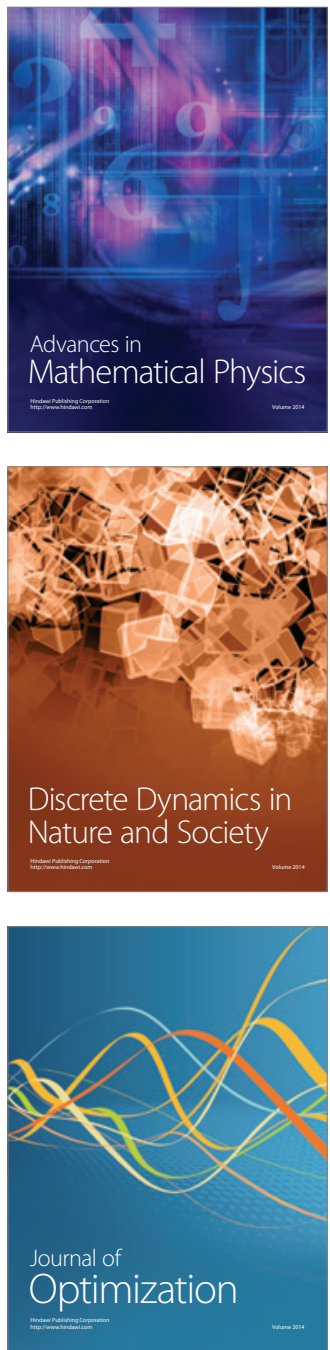